\title{
Transversalidades: gênero e feminismos em diversidade e movimento
}

\section{Entrelugares e Mobilidades.}

ASSIS, Gláucia de Oliveira; MINELLA, Luzinete Simões; FUNCK, Susana Bornéo (Orgs.) 1.ed.

Tubarão, SC: Editora Copiart, 2014, 592p. (Desafios Feministas, Volume 3)

A transversalidade da categoria gênero e as diversas expressões de desigualdades combatidas pela pluralidade de agendas feministas são assertivas centrais possíveis de serem extraídas da leitura de Entrelugares e Mobilidades (2014). Este terceiro volume integra a Coleção Desafios Feministas e é organizado por Gláucia de Oliveira Assis, Luzinete Simões Minella e Suzana Bornéo Funck. A partir dessa assertiva, a questão que a coletânea se propõe destrinchar é: quais são os desafios para os feminismos contemporâneos?

Essa é a problemática que nutre os outros dois volumes da Coleção. Assim como Entrelugares e Mobilidades (Volume 3), Linguagens e Narrativas (Volume 1) e Políticas e Fronteiras (Volume 2) reúnem trabalhos apresentados nas mesasredondas do $X$ Seminário Internacional Fazendo Gênero: Desafios Atuais dos Feminismos, que ocorreu em setembro de 2013, na Universidade Federal de Santa Catarina. A coletânea que apresentamos aqui é composta por 26 artigos, os quais abordam temas variados, mas que compõem uma coerência ao se analisar seu conjunto, visto estarem entrelaçados por algumas preocupações em comum. A partir de distintos campos das ciências humanas e de olhares interdisciplinares, os estudos de gênero que embasam esta coletânea trazem abordagens feministas que problematizam desigualdades nas relações de gênero em distintos contextos.

Na primeira parte, intitulada "Feminismos: trânsitos e movimentos", há um conjunto de seis artigos, cuja ênfase recai sobre questões relativas à mobilidade, ao deslocamento, à imigração, à organização política e aos feminismos transnacionais. São autoras desses textos: Adriana Piscitelli; Assumpta Sabuco Cantó; Beatriz Padilla; Ana Alcázar Campos; Ana Inés Mallimaci Barral; Bela Feldman-Bianco. Os desafios dos ativismos transnacionais se devem à necessidade de conciliar demandas locais (mas não necessariamente homogêneas), a expectativas e a problemáticas relativas aos fluxos e mobilidades globais.

Além de questões referentes à globalização e à etnicidade; à raça e à classe também são esmiuçadas na sua articulação com relações de gênero. A percepção generificada sobre a migração permite perceber as diferentes problemáticas vivenciadas por mulheres $e$ homens em situação de deslocamento; sobre mulheres em situações diversas de classe e etnia/ raça. Também permite refletir sobre sua agência, seja na busca pela migração como fator para mudança social, seja na resistência perante situações de violência em locais de acolhida e nos desafios para formação de redes e associações feministas transnacionais.

Outros dois artigos, um escrito por Rekha Pande e outro por Mariza Ruiz, enfatizam questóes sobre feminismos em planos mais localizados. Ambos inter-relacionam os movimentos políticos feministas com o contexto políitico local. Pande realiza uma análise histórica da descolonização e os efeitos atuais da globalização sobre meninas e mulheres na Índia. Ruiz permite que vislumbremos a importante participação das mulheres nos movimentos políticos de resistência à ditadura $e$ pela democratização no Uruguai. 
Por fim, um conjunto de mais três artigos é voltado para o campo rural, sobre mulheres em assentamentos do MST, camponesas e da agricultora familiar, expondo os desafios da organização e o ativismo políitico em contexto de globalização, responsável tanto pelas ameaças perpetradas pela economia capitalista, quanto pela abertura à possibilidade de transnacionalização de mulheres militantes. As autoras desses três artigos são Elisete Schwade, Gema Galgani Silveira Leite Esmeraldo e Hélène Guetat-Bernard.

A segunda parte da coletânea aborda as intersecções entre geração, classe, raça/etnia e gênero de modo mais enfático. Os artigos têm abordagem mais local, em sua maioria sobre o Brasil, com exceção do texto de Cecilia Rustoyburu, que trata sobre educação sexual e política de direitos para infância a partir da situação argentina, e o artigo de Silvia Maria Fávero Arend, que debate a entrada do Brasil no circuito internacional de adoção de crianças.

O entrecruzamento entre raça/etnia, gênero e classe é central no artigo de Ângela Figueiredo, a respeito das trabalhadoras domésticas, legislação trabalhista e a luta destas mulheres por maior acesso a direitos e cidadania. A autora enfatiza como a situação de negação histórica de direitos, a violência e o assédio sexual vivenciados por essas trabalhadoras estão totalmente vinculados ao fato de que são mulheres negras que atendem a essa ocupação em maior número no Brasil e ao significado dessa profissão construído em bases escravocratas pela sociedade brasileira.

A articulação entre esses marcadores sociais mencionados acima é a tônica da análise desenvolvida por Jurema Werneck, em um levantamento teórico que expõe os problemas do racismo patriarcal. Em uma inter-relação também com a religiosidade, Sônia Maria Giacomini reflete sobre mães-de-santo na umbanda e no candomblé e suas trajetórias como lideranças religiosas e políticas - universos que para essas mulheres e suas comunidades religiosas não são, tampouco precisam ser, irredutivelmente separados.

A relação entre gênero e geração centraliza a atenção de dez autoras, em nove artigos. Alda Britto da Motta enfatiza a invisibilidade de mulheres velhas nas produções acadêmicas e nas políticas públicas. As relações entre diferentes gerações de homens homossexuais é o tema abordado por Júlio Assis Simões.

Os outros artigos que trazem à tona a questão das gerações enfatizam a infância e a construção social das identidades de gênero, das hierarquias e do sexismo nessa etapa da vida.
Acrescenta-se o papel de instituições com o cuidado das crianças, no escopo de uma demanda histórica dos movimentos feministas, em especial aqueles motivados por mulheres trabalhadoras. Nessa proposta, a educação escolar, nos espaços da creche, da pré-escola e da educação infantil são analisados por: Maria Eulina Pessoa de Carvalho; Juliana Di Paula Queiroz Odinino; Verena Wiggers e Regina Ingrid Braganolo.

Um olhar sobre a sociologia da infância e a (in)visibilidade das diferenças de gênero é desenvolvido por Ana Cláudia Delfini Capistrano de Oliveira. Outros temas abordados são: educação sexual para infância, por Cecilia Rustoyburu; militância feminista e juventude, por Nilda Stecanela; e adoção internacional, por Silvia Maria Favero Arend. A preocupação que o Estado adote políticas mais eficazes em relação às questões de gênero nas instituições públicas concernentes às crianças e jovens é uma constante conclusão nesses textos. Arend aborda ainda demandas jurídicas envolvendo infância, família e adoção no contexto brasileiro e no plano internacional, expondo a questão da migração das crianças devido a situações de adoção.

A pluralidade de temas e situações sociais abordados nesses artigos, ao se intersecciona gênero e geração, tem sua importância traçada por garantir maior visibilidade a questões ainda pouco exploradas na literatura especializada, bem como trazer uma possibilidade analítica para esta inter-relação. O denso artigo de Oliveira propõe que se conduza à categoria geração o mesmo sabor desconstrucionista que já tem sido realizado em relação a gênero. A proposta é o uso de um enfoque relacional, posicionando adultos e crianças: afinal, como as crianças pensam a respeito de gênero? As crianças não poderiam ser vistas de maneira naturalizada, assexuada, homogênea, "assim, o mesmo processo de desconstrução do feminino pela categoria gênero está para ser feito na infância" (Ana Cláudia de OLIVEIRA, 2014, p. 526).

Outros três artigos abordam questões rurais. Temis Gomes Parente analisa o reassentamento de famílias a partir da implantação da Usina Hidrelétrica Estreito, entre os estados de Tocantins e Maranhão. O olhar voltado às questões específicas vividas pelas mulheres nessa situação permite à autora concluir que elas sofrem uma situação pior de desempoderamento, visto como, entre outros fatores, perda de autonomia, e, apropriando-se do dizer destas mulheres, de "serviço para agir". 
Por fim, tem-se o universo da pesca, abordado em dois textos a partir de enfoques diferentes. Maria do Rosário de Fátima Andrade Leitão analisa o papel crescente das lideranças femininas em movimentos sociais de pescadores artesanais, em Pernambuco em especial; ao passo em que o objeto abordado por Carlos Emanuel Sautchuk constitui a construção das masculinidades, a partir da corporalidade, das relações de alteridade e da socialização envoltas nos atos técnicos de pesca artesanal e profissional em uma localidade no estuário do Rio Amazonas.

Ao longo das últimas décadas, desde a emergência do feminismo, as remodelagens e desdobramentos têm sido tais que já não é possível pensar nesse termo no singular. Questões relativas à diferença foram sendo postas cada vez mais à tona em um contexto global em que não apenas a desigualdade de classe representa a tônica de nossos olhares, análises, críticas e propostas de transformação.

Pós-colonial, teoria do ponto de vista, construcionista social, multiétnica e multirracial ou pós-moderna são algumas das vertentes feministas que explicitam a variedade de sujeitos que se autoidentificam e/ou são identificados como mulheres, às quais uma total unidade não pode ser considerada. Nossas possibilidades de viver no mundo são entrecortadas por diferenças e por desigualdades de classe, de etnia, de raça, de geração, de religião, de orientação sexual, de trajetória de vida (em especial nos casos de migração e de ativismo político), de ocupação profissional, de escolaridade e de identificação de gênero em oposição à definição social baseada no sexo biológico. Nos estudos sobre os homens também sobressaem o trânsito entre essas diferenças, bem como as várias masculinidades.

O volume compreende, portanto, uma estratégia bem fundamentada em expor a transversalidade social do gênero e sua intersecção com outros marcadores sociais, expondo inclusive invisibilidades em alguns campos temáticos. Os artigos da coletânea apontam, de modo muito claro, que essas problemáticas são necessárias para repensar também políticas públicas - e que não podem ser implementadas ao largo de uma reflexão de como podem ser úteis para alterar ou reafirmar a desigualdade de gênero.

Trata-se de uma coletânea densa cuja abordagem plural baseia-se em pesquisas bem fundamentadas em contextos empíricos e levantamentos teóricos específicos, acrescentada da agilidade e a atualidade que se vivencia em eventos acadêmicos. A "mulher" (bem como o "homem") enquanto figura atemporal, a-histórica, universal e entidade discreta e unívoca é posicionada em questão. Entrelugares e Mobilidades demonstra $o$ interesse em aprofundar e em alargar o escopo das pesquisas sobre feminismos e relações de gênero e, dessa forma, permite um sopro de estímulo frente a outras possibilidades que podem emergir a partir do trabalho de pesquisadoras e militantes feministas.

Rosana Carvalho Paiva

Universidade Federal do Amazonas, Manaus, Amazonas, Brasil 